\title{
Exposure of honeybees (Apis mellifera) in Saskatchewan, Canada to organophosphorus insecticides
}

\author{
Yahya ALNAGgar ${ }^{1,2}$, Anja VogT ${ }^{2}$, Garry Codling ${ }^{2}$, Elsaied NAIEM ${ }^{1}$, Mohamed Mona ${ }^{1}$, \\ Amal SeIF ${ }^{1}$, Albert J. Robertson ${ }^{8}$, John P. Giesy, . 2,3,4,5,6,7 \\ ${ }^{1}$ Department of Zoology, Faculty of Science, Tanta University, Tanta 31527, Egypt \\ ${ }^{2}$ Toxicology Centre, University of Saskatchewan, 44 Campus Drive, Saskatoon, Saskatchewan S7N 5B3, Canada \\ ${ }^{3}$ Department of Veterinary Biomedical Sciences, University of Saskatchewan, Saskatoon, Saskatchewan, Canada \\ ${ }^{4}$ Department of Zoology, and Center for Integrative Toxicology, Michigan State University, East Lansing, MI, USA \\ ${ }^{5}$ Department of Biology \& Chemistry and State Key Laboratory in Marine Pollution, City University of Hong Kong, \\ Kowloon, Hong Kong, SAR, China \\ ${ }^{6}$ School of Biological Sciences, University of Hong Kong, Hong Kong, SAR, People's Republic of China \\ ${ }^{7}$ State Key Laboratory of Pollution Control and Resource Reuse, School of the Environment, Nanjing University, \\ Nanjing, People's Republic of China \\ ${ }^{8}$ Meadow Ridge Enterprises LTD, Saskatoon, Saskatchewan S7K 3J9, Canada
}

Received 22 September 2014 - Revised 22 January 2015 - Accepted 9 February 2015

\begin{abstract}
Concentrations of 14 organophosphorus insecticides (OPs) were measured in Apis mellifera L. (European honeybee) and hive matrices (honey and bee bread). Samples were collected from seven randomly selected colonies in central Saskatchewan during the summer of 2013. LC-MS/MS was used to identify and quantify individual OP by use of a modified quick easy cheap effective rugged safe (QuEChERS) method. Diazinon, dimethoate, and chlorpyrifos-oxon were the only OPs detected in honey with mean concentrations of $0.3,1.5$, and $0.2 \mathrm{ng} / \mathrm{g}$, wet mass (wm), respectively. Fenamiphos, chlorpyrifos, and chlorpyrifos methyl were the only OPs detected in bee bread, with mean concentrations of $0.4,2.7$, and $15.8 \mathrm{ng} / \mathrm{g}$, wm, respectively, while ethoprop, malathion, and dichlorvos were the only OPs detected in bees with mean concentrations of 1.4,3.7, and $889.2 \mathrm{ng} / \mathrm{g}$, wm, respectively. Total hazard quotients (HQs), based on lethality of bees exposed to OPs in honey and pollen consumed by bees ranged from 0.01 to 0.06 and based on lethality of bees from direct exposure to OPs ranged from 0.3 to 0.4 which suggests little hazard of OPs to Saskatchewan beehives.
\end{abstract}

honey / OPs / risk assessment / agriculture / honeybees

\section{INTRODUCTION}

Honeybees are important for both production of honey and pollination of crop plants. The European honeybee, Apis mellifera L., is an essential pollinator for agricultural crops in many

Electronic supplementary material The online version of this article (doi:10.1007/s13592-015-0357-y) contains supplementary material, which is available to authorized users.

Corresponding author: Y. ALNaggar, yehia.elnagar@science.tanta.edu.eg Manuscript editor: Monique Gauthier countries, pollinating $\$ 15$ to $\$ 20$ billion worth of crops in the USA alone and more than \$200 billion globally (VanEngelsdorp and Meixner 2010). The United States Department of Agriculture (USDA) estimates that one third of food consumed in North America is dependent on pollination by honeybees. Canada is a major food producer combining large areas $\left(415,000 \mathrm{~km}^{2)}\right.$ of agricultural land with a low population density. It has the 6th largest area of farmed arable land, with the province of Saskatchewan, making up $40 \%$ of this area, with an estimated 50,000 farms. In 2006, Saskatchewan produced $11.3 \times 10^{6} \mathrm{~kg}$ of honey, which accounted for $23 \%$ of all honey produced 
in Canada. Bees in Saskatchewan produce an average of $88 \mathrm{~kg}$ of honey per colony, meaning that the province supports approximately 128,000 commercial hives (http://www.agriculture.gov.sk. ca/Honey-Factsheet).

Honeybee colony losses pose a serious threat to both the apiculture industry and food production in crops requiring pollination. Increased colony failure has been estimated to cause losses in the agriculture economy of up to $\$ 75$ billion USD in 2007 (USDA 2007). It is not uncommon to lose hives during the over wintering period in Canada with an acceptable loss of $15 \%$ being described by Canadian beekeepers. However, over the winter of 2012-2013 in Canada, the average loss of honeybee colonies (colony mortality) or colonies too weak to be commercially productive was $28.6 \%$ (27 \% in Saskatchewan; CAPA 2013). Such increased rates of colony losses in Canada and globally has led to concerns that there may not be enough bees to sustain the required levels of pollination for agriculture crops and native species.

Although the putative causes of colony loss are still unclear and currently being investigated, results of some studies have suggested that extensive use of insecticides might be a factor in the increased rates of colony failure. Sequencing of the genome of the honeybee provides a possible explanation for their sensitivity to pesticides. Compared to genomes of other insects, that of the European honeybee is deficient in a number of genes encoding detoxification enzymes (Claudianos et al. 2006). As a consequence, honeybees might not be able to detoxify pesticides as rapidly as some other organisms. This might increase the length of time toxicants remain active within the body.

Canadian annual usage of pesticides has increased from 9.3 to 12.5 million kilograms from 2003 to 2008 (Health Canada, Consumer Product Safety, Pest Control Products Sales Report 2007 and 2008). The Prairie Provinces use approximately $60 \%$ of the pesticides in Canada, with Saskatchewan having the highest provincial usage (Brimbe 2005). Organophosphates (OPs) are a class of insecticides, which are highly toxic to bees. In the last two decades, they have been the most widely used insecticides. OPs have effective insecticidal properties and are used in Saskatchewan to control pests, such as grasshoppers, aphids, weevils, and crown borers as indicated in Table SI (Online Resource 1). Chlorpyrifos and diazinon are the most widely used in North America (Saskatchewan Usage Inventory 2003; Brimble 2005). In Saskatchewan, the highest atmospheric concentrations were observed for chlorpyrifos as it is the primarily OP used for grasshopper eradication (Raina et al. 2010), control of Bertha army worms, and Diamond back moths in canola and wheat midge. Organophosphates are not only used in agriculture but also in homes, gardens, and in veterinary practices.

Determination of OPs in food is a matter of public concern. Due to their global application, their residues constitute a potential risk to human health (Pico et al. 1996). Honeybees are exposed to a range of pesticides during pollination including OPs that have the potential to accumulate in the bees themselves or in their products (i.e., honey and wax). According to Health Canada Environmental Incident Reports in 2012, OPs including chlorpyrifos (Lorsban 4E) and dimethoate (Cygon 480 EC) were implicated in death of bees in Saskatchewan. In this investigation, we screened for OPs in bees and hive matrices from seven locations in central Saskatchewan during August 2013. The potential risks of OPs to bee colonies in this area were assessed in the absence of an environmental incidence.

\section{MATERIALS AND METHODS}

\subsection{Study areas}

The colony sampling for this study was performed on the 29th and 30th of August 2013 on seven independent apiaries that represent seven different locations within a $30-\mathrm{km}$ radius east and northeast of Saskatoon in Aberdeen and Blucher municipalities in Central Saskatchewan (Figure 1). The region has a continental climate with a warm season from May to September averaging a high temperature of $25^{\circ} \mathrm{C}$ and a winter average low temperature of $-21{ }^{\circ} \mathrm{C}$. Canola, alfalfa, wild flowers, willows, and dandelions represent the main source of nectar and pollen for bees in the vicinity of the apiaries, assuming a maximum bee range of 


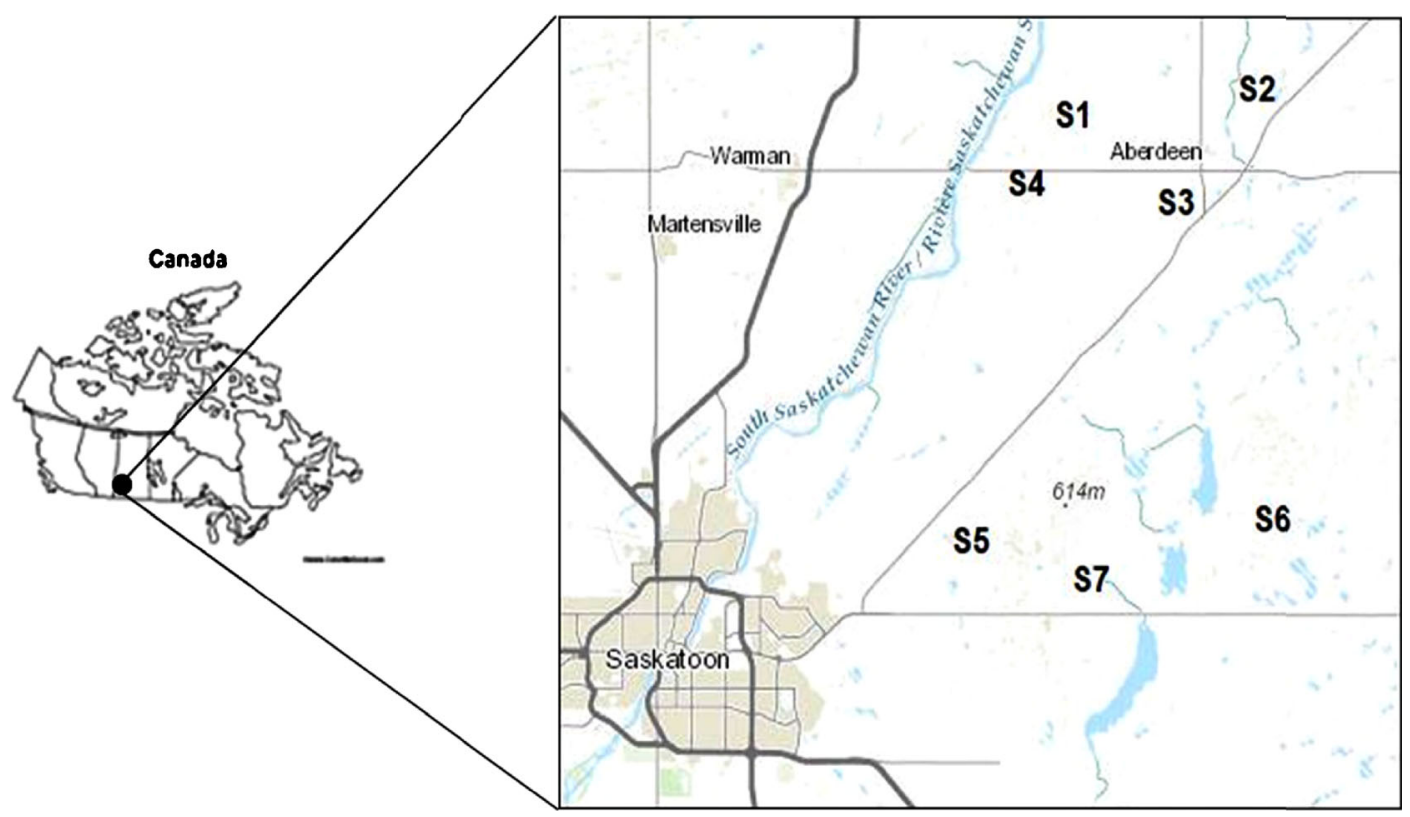

Figure 1. Sampling sites (S 1-7), Saskatoon, Saskatchewan, Canada.

$10 \mathrm{~km}$. In Saskatchewan, canola is the second most common crop grown commercially-a crop that did not exist 30 years ago (http://www.agriculture.gov. sk.ca/canola). Insecticides investigated in this study were selected based on previous studies (Rissato et al. 2007; Mullin et al. 2010; Chauzat et al. 2011; Wiest et al. 2011; Al Naggar et al. 2015), their toxicity (Johnson et al. 2010), and their use in Saskatchewan (Saskatchewan Usage Inventory 2003; Brimble 2005; Raina et al. 2010). A list of OPs insecticides used, their formulations, insects controlled, and registered crops were compiled according to the Ministry of Agriculture, Government of Saskatchewan, as indicated in Table SI (Online Resource 1).

\subsection{Experimental}

\subsubsection{Sampling}

Three hives (doubles) were randomly selected in each of seven apiaries containing 36 to 40 colonies with (16 to 18) deep Langstroth frames of bees per colony. These colonies were just finishing the honey flow, with high populations of foragers. Honey, pollen, and worker bees were collected from the hives at the end of August 2013. Fresh honey was squeezed out from the honey comb into a $50-\mathrm{mL}$ polyethylene Falcon tube (Fisher
Scientific). Samples of pollen were collected by cutting a $6-\mathrm{cm}^{2}$ piece of comb, containing stored pollen using a disposable plastic knife and placed in a 15-mL Falcon tube. Worker bees were carefully brushed directly into a disposable polyethylene bags. Worker bees were collected from the honey combs located on the farthest side walls of the hive from the entrance. Bees at the far wall from the entrance tend to be mostly foragers or older workers who would be expected to have potentially accumulated the highest levels of pesticide residues from foraging as well as consuming hive products (Al Naggar et al. 2013). All samples were transported and frozen at $-20{ }^{\circ} \mathrm{C}$ in the laboratory until extraction

\subsubsection{Chemicals and reagents}

All solvents (MeOH, MeCN, Hexane, etc.) were of HPLC grade or better and tested for OP contamination prior to use. Magnesium sulfate $\left(\mathrm{MgSO}_{4}\right)$ and anhydrous sodium sulfate $(\mathrm{NaAc})$ were from (Sigma Aldrich, Ca.). Pesticide standards were all technical grade ( $>98 \%$ purity, Accu Standard, New Haven, CT, USA). Individual stock standard solutions were prepared by dissolving $10 \mathrm{mg}$ of each compound in methanol and mixed compound calibration solutions were prepared from the stock. Matrix-matched standards were prepared in the same concentration as that of 
calibration solutions, by adding appropriate amounts of standards to the control matrix, and used to calculate the matrix limit of quantifications (LOQs).

\subsubsection{Extraction and cleanup}

The QuEChERS method was used in the extraction and cleanup, based on that described by Lehotay et al. (2005) and adapted for the lesser mass used in this study. A 3-g ( \pm 0.5$)$ aliquant of sample (bee, honey, or bread) was weighed into a $50-\mathrm{mL}$ falcon tube and fortified with $100 \mu \mathrm{L}$ of $100 \mathrm{ng} / \mathrm{mL}$ process control spiking solution (PCS) containing dimethoate-d6. Twenty-seven milliliters of extraction solution (44\% deionized water, $55 \%$ acetonitrile, and $1 \%$ glacial acetic acid) was added, followed by $6 \mathrm{~g} \mathrm{MgSO}_{4}$ and $1.5 \mathrm{~g} \mathrm{NaAc}$. Tubes were sealed and vortexed for $1 \mathrm{~min}$ and centrifuged for $10 \mathrm{~min}$ at $4000 \mathrm{~g} ; 15 \mathrm{~mL}$ of the supernatant was transferred to a falcon tube and evaporated under $\mathrm{N}_{2}$ stream to $\sim 4 \mathrm{~mL}$.

C18 SPE cartridges $(1000 \mathrm{mg})$ with $2 \mathrm{~g} \mathrm{MgSO}_{4}$ added to the top of each column conditioned with $5 \mathrm{~mL} 1 \%$ acetic acid/MeCN were used for sample cleanup. The extract was transferred onto the SPE column with washings and collected in a $15-\mathrm{mL}$ falcon tube and the SPE column and rinsed with $10 \mathrm{~mL}$ of $1 \%$ acetic $\mathrm{acid} / \mathrm{MeCN}$. Vacuum was applied for $1 \mathrm{~min}$ to draw out the last of the solvent from the cartridge and samples concentrated to $2 \mathrm{~mL}$ under $\mathrm{N}_{2}$. A 1-mL aliquot of this extract was transferred to a $2-\mathrm{mL}$ tube containing $0.05 \mathrm{~g}$ primary secondary amine (PSA) and $0.15 \mathrm{~g} \mathrm{MgSO}_{4}$. Samples were vortexed for $1 \mathrm{~min}$ and centrifuged at $10,000 \mathrm{~g}$ for $1 \mathrm{~min}$, the final extract filtered through a 13-mm 0.2- $\mu \mathrm{m}$ nylon syringe filter (Whatman UK), and collected in a 2-mL amber GC vial. A subsample of each filtered sample $(100 \mu \mathrm{L})$ was transferred to an autosampler vial fitted with glass insert and internal standard (IS) (malathion-d10) was introduced into extracts prior to analysis by LC-MS/MS.

\subsubsection{Quantification of OPs by LC-MS/MS}

Separation of target analytes was performed by HPLC (Agilent Technologies) on a Kinetex C18 100A column (Phenomenex, $100 \times 4.6 \mathrm{~mm}, 5-\mu \mathrm{m}$ particle size), using water (A) and methanol (B) as solvents at a flow rate of $250 \mu \mathrm{m} / \mathrm{min}$. The solvent gradient was $10 \% \mathrm{~B}$ increasing to $85 \% \mathrm{~B}$ over $15 \mathrm{~min}$, then increasing to $95 \% \mathrm{~B}$ at $25 \mathrm{~min}$, before returning to $10 \% \mathrm{~B}$ and holding for $5 \mathrm{~min}$. Mass spectra were collected by use of a triple quadruple, tandem mass spectrometer fitted with an electrospray ionization source (Applied Biosciences SCIEX 3000). Operating in positive ionization mode (MRM), using the following parameters: capillary voltage $5.5 \mathrm{kV}$, temperature $450{ }^{\circ} \mathrm{C}$; nebulize, curtain, and collision gas was set at 10,8 , and 4 respectively. Quantification was by Analyst 1.4.1 software (SCIEX, Applied Biosciences Foster City, CA). A list of target ions is given in Table SII (Online Resource 1).

\subsection{Assessment of hazard}

Toxicity of OPs to the European honeybee, expressed as the acute, oral LD50 was compiled from literature as shown in Table SIII (Online Resource 1). The hazard characterization scheme applied for assessing risks of foliar sprayed pesticides to pollinators was based on work described in the White Paper (US Environmental Protection Agency (USEPA), Health Canada Pest Management Regulatory Agency (PMRA), California Department of Pesticide Regulation (CDPR) 2012). Uncertainty was assessed by calculating the maximum possible exposure (worst case) and least possible exposure (best case) scenarios because concentrations of some OPs were $<$ LOQ. Since pollen and honey represent as primary sources of exposure for both larval and adult stages of bees, both were included in the investigation. Based on positive detections of OPs residues in honey and pollen, median, and 95th centile values were used for calculating total daily intake (TDI) for best and worst case, respectively. For OPs that not were detected, limits of detection (LODs) were used as surrogate values in the worst case exposure scenario while were set to zero (0.0) in the best case scenario (Al Naggar et al. 2015). Total daily intake (TDI) of pesticides received by bees via food was calculated based on total food consumption rate (TFR) for adult worker bees estimated to be $292 \mathrm{mg}$ / day for nectar (USEPA, PMRA, CDPR 2012) and $9.5 \mathrm{mg} /$ day for pollen for nurse bees (Crailsheim et al. 1992) (Eq. 1).

$$
\mathrm{TDI}=\mathrm{OPH}^{*} \mathrm{TFRH}+\mathrm{OPP} * \mathrm{TFRP}
$$

Where OPH refers to concentrations of OPs detected in honey, OPP refers to concentrations of OPs detected in the pollen, TFRH refers to rate of consumption of honey, and TFRH refers to rate of consumption of the pollen. 
Because the mode of toxic action of OPs is mainly via inhibition of acetylcholinesterase activity, a toxic unit approach was used. HQ for individual OP was calculated based on TDI of OPs in honey and pollen divided by the $\mathrm{LD}_{50}$ for each OP. The overall HQ was the sum of HQs for individual OP (Eq. 2).

HQs $=($ TDI honey + TDI pollen $) /$ acute oral LD50

To assess the potential effects of OPs to worker bees during summer, tier I screening-level assessments (HQs) were used based on detected OPs in bees (body burden) with zero (0.0) and (LODs) used as surrogate values for concentrations of OPs that were not detected for best and worst case, respectively. Median and 95th centile values of OPs detected in bee body burden were also used to calculate HQs. The total concentrations of OPs in bee's body burden could be due to direct contact and/or dietary exposure (uncertainty factor). HQs for individual OP were calculated as the ratio of measured concentrations of individual OP in bee's body burden divided by the $\mathrm{LD}_{50}$ for each $\mathrm{OP}$, respectively (Eq. 3).

$$
\text { HQs = OPs (body burden) / acute oral LD50 }
$$

If the sum of HQs of individual OP exceeded the levels of concern (LOC) (i.e., concentration of an hazardous substance greater than which there may be effects on living organisms exposed to it even for a short period) of 0.4 for acute lethality based on work described in the White Paper (USEPA, PMRA, CDPR 2012) or 0.1 over a 1-day consumption period set by the European Food Safety Authority (EFSA 2013) then higher-tier assessments (tier II and tier III) would be evaluated to obtain a more realistic measure of the risk of OPs to honeybees as indicated in Figure S1 (see supplementary material). The margin of exposure (MOE) is the inverse of the HQ. An HQ of 0.1 would have an MOE of 10 . That is, concentrations would need to be tenfold greater than $\mathrm{LD}_{50}$ to cause $50 \%$ lethality of bees. This "margin" is essentially the established "safety buffer" between the toxicity effect level dose and the predicted exposure dose.

\subsection{Quality control and assessment}

Precision and accuracy of the modified QuEChERS method used to quantify concentrations of OPs in honeybees and their products, honey and pollen were obtained through the analysis of six replicates for each spiked matrix honey, pollen, and bees. Samples were spiked at concentrations ranging from 600 to $1800 \mathrm{ng} / \mathrm{g}$ which represents 30 to $90 \mathrm{ng} / \mathrm{g}$ at final injection according to each individual OP and the extraction protocol. Recoveries of individual OP were determined by the use of external standards. Mean recoveries were between 86 and $106 \%$, with a relative standard deviation (RSD) $<14 \%$ for honey, 75-117\% with RSD $<18 \%$ for pollen, and $64.5-102 \%$ with $\mathrm{RSD}<19$ for bees. Limits of detection (LODs) of pesticides were defined based on a signal three times the background noise $(\mathrm{S} / \mathrm{N}=3)$, ranged from $0.05 \mathrm{ng}$ phorate/g, wet mass (wm) to $21.5 \mathrm{ng}$ dichlorvos/g, wm for honey; $0.07 \mathrm{ng}$, wm diazinon $/ \mathrm{g}$, wm to $12.2 \mathrm{ng}$ dimethoate $/ \mathrm{g}$, wm for pollen; and $0.02 \mathrm{ng}$ malathion/g, wm to $10.7 \mathrm{ng}$ dimethoate/g, wm for bees (Table I). Limits of quantification (LOQs) of pesticides were calculated based on a signal that was ten times the background noise $(\mathrm{S} / \mathrm{N}=10)$. Application of liquid chromatography allows the analysis of pesticides regardless of their stability and volatility including polar and thermolabile pesticides.

Statistical analysis was not applied in this study due to the limited number of samples and limited detection of compounds in all three matrices; however, the range of each OP residue detected (maximum, minimum, mean, median, and 95th centile) in each matrix was reported based on positive detections.

\section{RESULTS}

Of the 14 OPs investigated in 67 samples of bees $(n=16)$, honey $(n=30)$, and pollen $(n=21)$, dicrotophos, coumaphos, phorate, profenofos, and fenthion were never detected. Diazinon, dimethoate, and chlorpyrifos-oxon were the only OPs detected in honey with mean concentrations of positive samples of $0.25,1.5$, and $0.2 \mathrm{ng} / \mathrm{g}$, wm, respectively. In pollen, fenamiphos, chlorpyrifos and chlorpyrifos methyl were the only OPs detected with mean concentrations of $0.4,2.7$, and $15.8 \mathrm{ng} / \mathrm{g}$, wm, respectively. In bees, ethoprop, malathion, and dichlorvos were detected with mean concentration of 1.4, 3.7, and $899.2 \mathrm{ng} / \mathrm{g}$, wm, respectively (Table II). In general, concentrations of OPs detected in this study were lesser or similar to those detected in previous studies for OPs in bees, honey, or pollen (Table SIII Online Resource 1). 


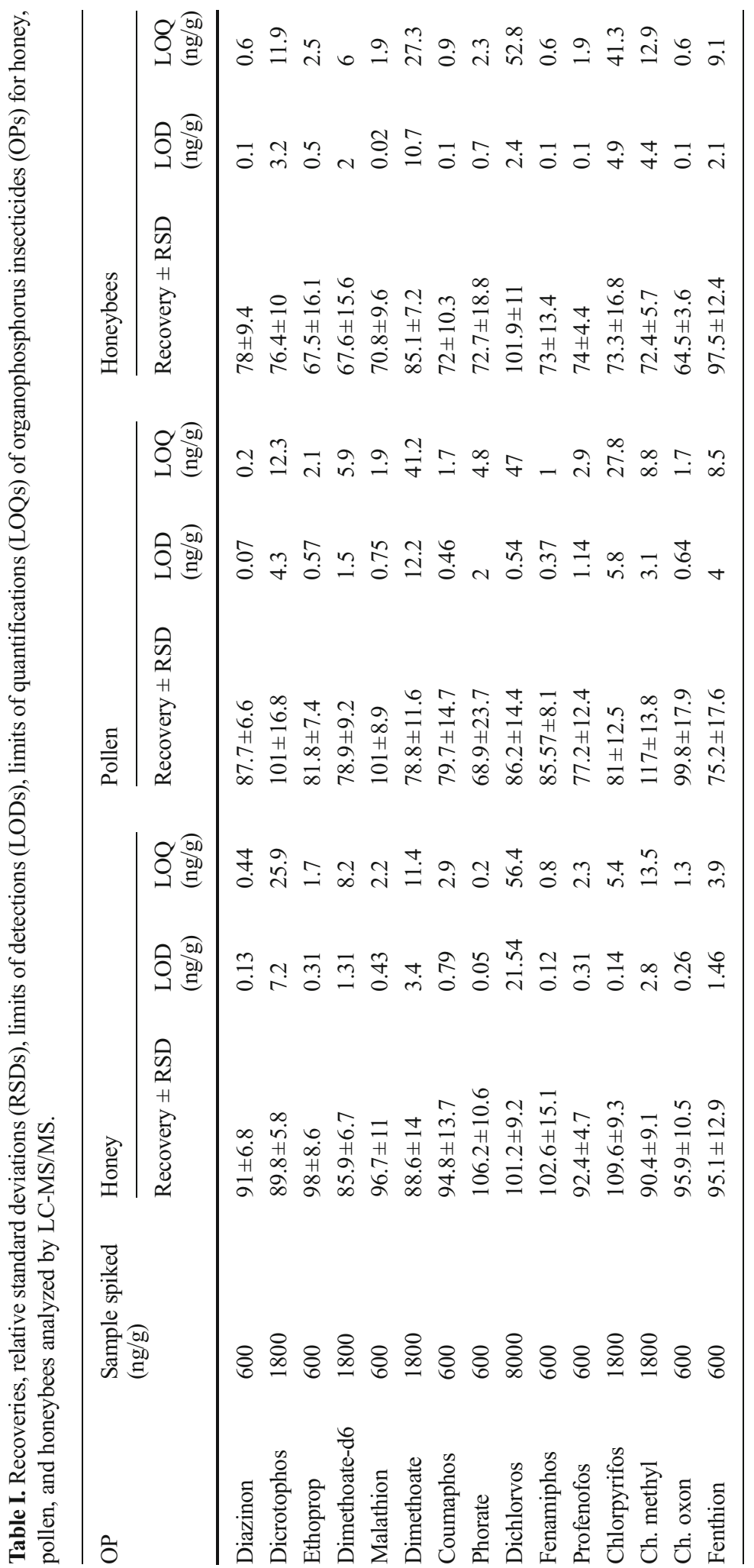


Table II. Organophosphorus pesticides (OPs) (ng/g, wm) detected in honey, pollen, and honeybees collected from Saskatchewan, Canada in summer 2013.

\begin{tabular}{llllllll}
\hline Matrix & OP & $\begin{array}{l}\text { No. of positive } \\
\text { samples }\end{array}$ & $\begin{array}{l}\text { Minimum } \\
(\mathrm{ng} / \mathrm{g})\end{array}$ & $\begin{array}{l}\text { Maxiumum } \\
(\mathrm{ng} / \mathrm{g})\end{array}$ & $\begin{array}{l}\text { Median } \\
(\mathrm{ng} / \mathrm{g})\end{array}$ & $\begin{array}{l}\text { 95th centile } \\
(\mathrm{ng} / \mathrm{g})\end{array}$ & $\begin{array}{l}\text { Mean } \\
(\mathrm{ng} / \mathrm{g})\end{array}$ \\
\hline Honey & Diazinon & $3 / 30$ & 0.3 & 0.3 & 0.3 & 0.3 & 0.3 \\
& Dimethoate & $1 / 30$ & 1.5 & 1.5 & 1.5 & 1.5 & 1.5 \\
& Ch. oxon & $2 / 30$ & 0.2 & 0.2 & 0.2 & 0.2 & 0.2 \\
Pollen & Fenamiphos & $5 / 21$ & 0.3 & 0.3 & 0.3 & 0.3 & 0.4 \\
& Chlorpyrifos & $3 / 25$ & 1.7 & 3.3 & 2.37 & 0.3 & 2.7 \\
& Ch. methyl & $5 / 21$ & 2.8 & 28.8 & 13.1 & 27.4 & 15.8 \\
Bees & Ethoprop & $1 / 16$ & 1.4 & 1.4 & 1.4 & 1.4 & 1.4 \\
& Malathion & $1 / 16$ & 3.7 & 3.7 & 3.7 & 3.7 & 3.7 \\
& Dichlorvos & $1 / 16$ & 899.2 & 899.2 & 899.2 & 899.2 & 899.2 \\
\hline
\end{tabular}

\section{DISCUSSION}

Results of this study demonstrate that in the vicinity of Saskatoon, Saskatchewan, OP insecticides were detected more frequently in stored pollen than bees and honey (Figure 2). The greater frequencies of detection of OPs in pollen samples might be because of the anatomy of flowers which enables nectar to be protected more than pollen from exposure to spray droplets (Willmer 2011). Moreover, nectar, water, and honeydew are carried internally in the "honey stomach" by bees (Gary 1975; Snodgrass 1975). Residues of pesticides in the honey stomach are more likely to be absorbed and metabolized, which would reduce the amount transferred to the hive. Foraging bees carrying increased levels or doses of pesticides would be less likely to survive and return back to the colony. The different chemical composition of honey (water and sugar) and pollen (more lipophilic) may be another reason for the greater frequencies of detections of OPs in the pollen and explain the variation in OPs seen in each matrix.

Of those compounds detected, some were detected at greater frequency. Chlorpyrifos-ethyl

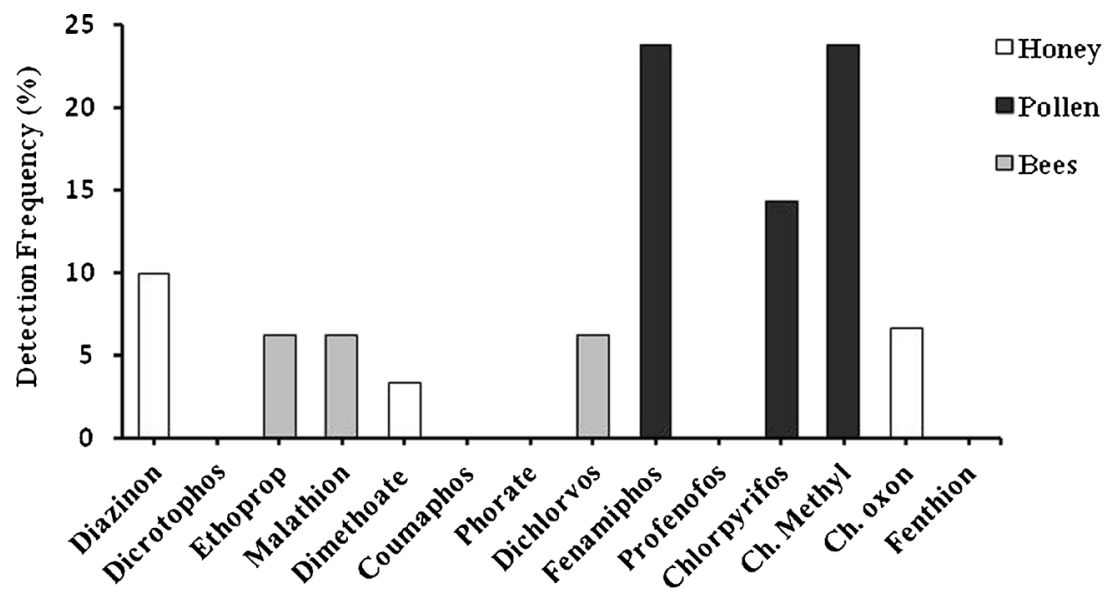

Figure 2. Percentages (\%) of positive samples for organophosphorus insecticides (OPs) detected in honey, pollen, and honeybees collected from Saskatchewan, Canada in summer 2013. 
Table III. Tier I hazard quotients (HQs) for lethality of bees exposed to organophosphorus insecticides (OPs) in honey and pollen consumed by bees in Saskatchewan, Canada during summer 2013.

\begin{tabular}{|c|c|c|c|c|c|c|c|}
\hline \multirow[t]{2}{*}{ Pesticide } & \multirow{2}{*}{$\begin{array}{l}\text { Oral LD50 } \\
\text { (ng/bee) }\end{array}$} & \multicolumn{4}{|c|}{ Total daily intake (TDI) (ng/bee/day) } & \multicolumn{2}{|c|}{ HQs (honey and pollen) } \\
\hline & & $\begin{array}{l}\text { Honey } \\
\text { (best case) }\end{array}$ & $\begin{array}{l}\text { Honey } \\
\text { (worst case) }\end{array}$ & $\begin{array}{l}\text { Pollen } \\
\text { (best case) }\end{array}$ & $\begin{array}{l}\text { Pollen } \\
\text { (worst case) }\end{array}$ & Best case & Worst case \\
\hline Diazinon & 168 & 0.07 & 0.07 & 0.00 & 0.00 & 0.000 & 0.000 \\
\hline Dicrotophos & 137.6 & 0.00 & 2.10 & 0.00 & 0.04 & 0.000 & 0.016 \\
\hline Ethoprop & 5560 & 0.00 & 0.09 & 0.00 & 0.01 & 0.000 & 0.000 \\
\hline Malathion & 335.2 & 0.00 & 0.13 & 0.00 & 0.01 & 0.000 & 0.000 \\
\hline Dimethoate & 129.6 & 0.44 & 0.44 & 0.00 & 0.12 & 0.003 & 0.004 \\
\hline Coumaphos & 14,390 & 0.00 & 0.13 & 0.00 & 0.00 & 0.000 & 0.000 \\
\hline Phorate & 196 & 0.00 & 0.01 & 0.00 & 0.02 & 0.000 & 0.000 \\
\hline Dichlorvos & 218.4 & 0.00 & 6.29 & 0.00 & 0.01 & 0.000 & 0.029 \\
\hline Fenamiphos & 1870 & 0.00 & 0.04 & 0.00 & 0.00 & 0.000 & 0.000 \\
\hline Profenofos & 95 & 0.00 & 0.09 & 0.00 & 0.01 & 0.000 & 0.001 \\
\hline Chlorpyrifos & 67.8 & 0.00 & 0.04 & 0.02 & 0.03 & 0.000 & 0.001 \\
\hline Ch. methyl & 110 & 0.00 & 0.82 & 0.13 & 0.26 & 0.001 & 0.010 \\
\hline Fenthion & 251.2 & 0.00 & 0.43 & 0.00 & 0.00 & 0.000 & 0.002 \\
\hline \multicolumn{6}{|l|}{ Sum } & 0.01 & 0.1 \\
\hline \multicolumn{6}{|c|}{ Margin of exposure (MOE) } & 189 & 16 \\
\hline
\end{tabular}

(CPY) and chlorpyrifos methyls were detected in 14 and $24 \%$ of all pollen samples, respectively. But the active metabolite chlorpyrifos oxon (CPYO) was detected in only $7 \%$ of samples of honey (Figure 2). CPY is the most widely used organophosphorus insecticide, available in a granular formulation for treatment in soil or several flowable formulations (Solomon et al. 2014). There was a high usage of chlorpyrifos in 2003 in Canada with the majority of usage in the Prairie Provinces (Saskatchewan Usage Inventory 2003; Brimble 2003). Usage of chlorpyrifos in Saskatchewan in 2003 was $205,562 \mathrm{~kg}$ relative to 7267 and $121,824 \mathrm{~kg}$ in 2001 and 2002, respectively (Hall 2010). Usage of chlorpyrifos in 2008 remained $>500,000 \mathrm{~kg}$ in Canada with the largest usage still expected in Saskatchewan and Alberta (Health Canada, Consumer Product Safety, Pest Control Products Sales Report for 2007 and 2008).

CPY is an inhibitor of acetylcholinesterase (AChE) and is potentially toxic to most insects including bees. Due to its greater potency and relatively large use in crops in Saskatchewan,
CPY had the greatest HQ but did not exceed the LOC of 0.4 set by the US EPA, PMRA, and CDPR for the tier I threshold for moving to more refined approaches to assessing the potential for adverse effects. A Health Canada report (2012), measuring CPY in reservoirs where seeded crops were grown in the provinces of Saskatchewan and Alberta, found traces of CPY in less than half of the study sites during spring and summer 2003/ 2004; however, there were some reports where CPY and dimethoate use may have been the direct cause of toxic effects on some Saskatchewan beehives in 2012.

Fenamiphos, which detected as chlorpyrifos methyl in $24 \%$ of pollen samples, is an insecticide registered nationally in Canada for control of nematodes and insects in agricultural and commercial areas. Other pesticides such as dimethoate and diazinon were detected in only 3 and $10 \%$ of honey samples, respectively, and malathion, ethoprop, and dichlorvos were detected in only $6 \%$ of bee samples which may indicate their limited application in the study area (Figure 2). 
Coumaphos often employed in hives for control of mites was not detected in any samples of honey, pollen, and bees. The apiaries in this study group were operated by Meadow Ridge Enterprises LTD, where varroa populations are managed by using resistant stock and non-synthetic miticides, such as oxalic liquid and thymol. This differs from previous studies where coumaphos was the most common OP associated with beehives (Ghini et al. 2004; Mullin et al. 2010; Bernal et al. 2010). This may be due to a shift in use as the Varroa mites, for which the treatment is often applied have become more resistant and attitudes of beekeepers has changed in some cases to minimize pesticide exposure (Currie et al. 2010).

Recently, the need for further research on the drivers of the "pollinator crisis" was called for and, in particular, the need to better understand responses of pollinator communities to complex environmental stressors (Ghazoul 2005). To fill this gap, the potential risks to Saskatchewan beehives from exposure to OP insecticides were evaluated by using a simplified hazard assessment approach. The scheme incorporated tier I (worst case) screening-level assessments that calculate hazard quotients (HQs) based on ratios of estimated exposure by dietary uptake of OPs in nectar and pollen. HQs for lethality of bees exposed to OPs in honey and pollen consumed by bees were calculated to range from $0.01-0.1$ for the best and worst case, respectively (Table III). The proposed tier I scheme includes an acute oral level of concern (LOC of 0.4) HQ for adult and larval honeybees (USEPA, PMRA and CDPR 2012) and (LOC of 0.1) over a 1-day consumption period (UFSA 2013). Calculated HQs were less than the level of concern ( 0.4 for acute tests) and not exceeded the UFSA LOC of (0.1) for both best and worst case. This result suggests that the potential for acute lethality from consumption of OPs in the diet was minimal. HQs for lethality of bees exposed to OPs directly and or dietary exposure (uncertainty factor) were calculated to range from $0.3-0.4$ for the best and worst case, respectively (Table IV).

Dichlorvos was detected in a high concentration of 899.2 in only $6 \%$ of bee samples $(n=16)$. Therefore, $85 \%$ of the calculated HQs for both the best and worst case were due to dichlorvos. HQs were less than the level of concern ( 0.4 for acute

Table IV. Tier I hazard quotients (HQs) for lethality of bees from direct exposure to organophosphorus insecticides (OPs) in Saskatchewan, Canada during summer 2013.

\begin{tabular}{|c|c|c|c|c|c|c|}
\hline $\mathrm{OP}$ & $\begin{array}{l}\text { Oral LD50 } \\
\text { (ng/bee) }\end{array}$ & $\begin{array}{l}\text { Conc. detected } \\
\text { (ng/g) }\end{array}$ & $\begin{array}{l}\text { Conc. (ng/g) } \\
\text { best case }\end{array}$ & $\begin{array}{l}\text { Conc. (ng/g) } \\
\text { worst case }\end{array}$ & $\begin{array}{l}\text { HQs best } \\
\text { case }\end{array}$ & $\begin{array}{l}\text { HQs worst } \\
\text { case }\end{array}$ \\
\hline Diazinon & 168 & ND & 0 & LOD $(0.1)$ & 0.00 & 0.00 \\
\hline Dicrotophos & 137.6 & ND & 0 & LOD (3.2) & 0.00 & 0.00 \\
\hline Ethoprop & 5560 & 1.36 & 1.36 & 1.36 & 0.00 & 0.00 \\
\hline Malathion & 335.2 & 3.74 & 3.74 & 3.74 & 0.00 & 0.00 \\
\hline Dimethoate & 129.6 & ND & 0 & LOD (10.7) & 0.00 & 0.01 \\
\hline Coumaphos & 14,390 & ND & 0 & LOD $(0.1)$ & 0.00 & 0.00 \\
\hline Phorate & 196 & ND & 0 & LOD (0.7) & 0.00 & 0.00 \\
\hline Dichlorvos & 218.4 & 899.19 & 899.19 & 899.19 & 0.33 & 0.33 \\
\hline Fenamiphos & 1870 & ND & 0 & LOD (0.1) & 0.00 & 0.00 \\
\hline Profenofos & 95 & ND & 0 & $\operatorname{LOD}(0.1)$ & 0.00 & 0.00 \\
\hline Chlorpyrifos & 67.76 & ND & 0 & LOD (4.9) & 0.00 & 0.04 \\
\hline Ch. methyl & 110 & ND & 0 & LOD (4.4) & 0.00 & 0.00 \\
\hline Fenthion & 251.2 & ND & 0 & LOD (2.1) & 0.00 & 0.00 \\
\hline \multicolumn{5}{|l|}{ Sum } & 0.3 & 0.4 \\
\hline \multicolumn{5}{|c|}{ Margin of exposure (MOE) } & 3.3 & 2.5 \\
\hline
\end{tabular}


tests) for the best case and equal but not exceeded the level of concern for the worst case. Therefore, those higher-tier assessments (tier II and tier III) were not indicated by the results of this study.

Since colony losses usually occur in winter, lethality of individual worker bees exposed to insecticides during summer is likely not a major cause of colony decline. In summer months, the worker bees have a short lifespan of only a few weeks, but winter bees have a longer life span and would be more affected by pesticide contamination of hive products. Thus, stored honey and or pollen could be a chronic source of such toxic substances (Faucon et al. 2005; Chauzat et al. 2006). Intoxication of bees by these pesticides would mainly happen in winter because the stored pollen is practically the only protein source that the bees consume during winter (Seeley et al. 1985). In this study, greater concentrations of OPs were observed in stored pollen collected during summer. Consequently, losses of beehives in Saskatchewan might be attributed in some cases to chronic exposure of bees to pesticides in stored honey and pollen collected during summer months and consumed during the long winter season. While this is unlikely due to minimal hazard calculated from dietary exposure of honeybees to OPs in honey and pollen ( 0.01 to 0.1$)$ for the best and worst case, respectively, it might be a contributing factor in a complex of multiple etiologies or possibly interactions between and among stressors, including nutrition, changes in climate, infestations with mites, and viral diseases (Fairbrother et al. 2014). While the information presented here is useful as an initial benchmark, more complex study designs would be needed to investigate these potential interactions. This study provides the necessary information on exposure concentrations of OPs that would be appropriate to use in more controlled studies of potential complex interactions between insecticides, parasites, and diseases caused by bacteria and/or viruses.

In conclusion, bee bread (stored pollen) was the most contaminated by OPs while honey was the least contaminated. HQs based on lethality of bees exposed to OPs in the diet via consumption of honey and pollen were less than the level of concern and did not exceed the level of concern in case of direct exposure to OPs, which suggested minimal potential lethality from direct and or dietary exposure of beehives to OPs in Saskatchewan.

\section{ACKNOWLEDGMENTS}

The authors wish to acknowledge the support of grants from the Egyptian Fellowship and Missions Sector, Engineering Research Council of Canada (Project \# 326415-07), Western Economic Diversification Canada (Project \# 6578 and 6807), an instrumentation grant from the Canada Foundation for Infrastructure, and Meadow Ridge Enterprises LTD for providing apiaries and assistance with sampling. Prof. Giesy was supported by the Canada Research Chair program, a Visiting Distinguished Professorship in the Department of Biology and Chemistry and State Key Laboratory in Marine Pollution, City University of Hong Kong; the 2012 "High Level Foreign Experts" (\#GDW20123200120) program, funded by the State Administration of Foreign Experts Affairs, the P.R. China to Nanjing University; and the Einstein Professor Program of the Chinese Academy of Sciences. The research was supported by a Discovery Grant from the Natural Science and Engineering Research Council of Canada (Project \# 326415-07) and a grant from the Western Economic Diversification Canada (Project \# 6578, 6807, and 000012711).

Exposition d'abeilles (Apis mellifera) aux insecticides organophosphorés dans le Saskatchewan, Canada

Miel / évaluation des risques / agriculture / abeille / toxicologie

Organophosphatinsektizidexposition von Honigbienen (Apis mellifera ) in Saskatchewan, Kanada

Honig / ops / Risikoabschätzung / Landwirtschaft / Honigbienen

\section{REFERENCES}

Al Naggar, Y., Naiem, E., Mona, M., Seif, A. (2013) Honey bees and their products as a bioindicators of environmental pollution with heavy metals. Mellifera $13(26)$, 10-20

Al Naggar, Y., Codling, G., Vogt, A., Naiem, E., Mona, M., Seif, A., Giesy, J. (2015) Organophosphorus insecticides in honey, pollen and bees (Apis mellifera L.) and 
their potential hazard to bee colonies in Egypt. Ecotox. Environ. Safe. 114, 1-8

Bernal, J., Garrido-Bailon, E., Del Nozal, M.J., GonzalezPorto, A.V., Martin-Hernandez, R., Diego, J.C., Jimenez, J.J., Bernal, J.L., Higes, M. (2010) Overview of pesticides in stored pollen and their potential effect on bee colony (Apis mellifera) losses in Spain. J. Econ. Entomol. 6, 1964-1971

Brimble, S. (2003) Pesticide Utilization in Canada: A Compilation of Current Sales and Use Data. Environment Canada, Ottawa

Brimble, S.; Bacchus, P.; Caux, P. Y. (2005) Pesticide Utilization in Canada: A Compilation of Current Sales and Use Data. Environment Canada, Gatineau, QC

CAPA, CAPA Statement on Honey Bee Wintering Losses in Canada (2013) http:/capabees.org/content/uploads/ 2013/06/2013-CAPA-Statement-on-ColonyLosses.pdf. Accessed 15 January 2015

Chauzat, M.P., Faucon, J.P., Martel, A.C., Lachaize, J., Cougoule, N., Aubert, M. (2006) A survey of pesticide residues in pollen loads collected by honey bees in France. J. Econ. Entomol. 99, 253-262

Chauzat, M.P., Martel, A.C., Cougoule, N., Porta, P., Lachaize, J., Zeggane, S., Aubert, M., Carpentier, P., Faucon, J.P. (2011) An assessment of honeybee colony matrices, Apis mellifera (Hymenoptera: apidae) to monitor pesticide presence in continental France. Environ. Toxicol. Chem. 30, 103-111

Claudianos, C., Ranson, H., Johnson, R.M., Biswas, S., Schuler, M.A., et al. (2006) A deficit of detoxification enzymes: pesticide sensitivity and environmental response in the honeybee. Insect Mol. Biol. 15, 615636

Crailsheim, K., Schneider, L.H.W., Hrassnigg, N., Buhlmann, G., Brosch, U., et al. (1992) Pollen consumption and utilization in worker honeybees (Apis mellifera carnica): Dependence on individual age and function. J. Insect Physiol. 38, 409-419

Currie, R., Pernal, S., Guzmán-Novoa, E. (2010) Honey bee colony losses in Canada. J. Apic. Res 1, 104106

European Food Safety Authority (2013) EFSA Guidance Document on the risk assessment of plant protection products on bees (Apis mellifera, Bombus spp. and solitary bees). EFSA J 11(7), 3295. $268 \mathrm{pp}$

Fairbrother, A., Purdy, J., Anderson, T., Fellk, R. (2014) Risks of Neonicotinoid Insecticides to Honeybees. Environ. Toxicol. Chem. 4, 719-731

Faucon, J.P., Aurieres, C., Drajnudel, P., Mathieu, L., Ribiere, M., Martel, A.C., Zeggane, S., Chauzat, M.P., Aubert, M. (2005) Experimental study on the toxicity of imidaclopridgiven in syrup to honey bee (Apis mellifera) colonies. Pest Manag. Sci. 61, 111-125

Gary, N.E. (1975) Activities and Behavior of Honey Bees. In: Veatch, E. (ed.) The Hive and the Honey Bee, pp. 185-264. Dadant \& Sons, Hamilton, IL
Ghazoul, J. (2005) Buzziness as usual? Questioning the global pollination crisis. Trends. Ecol. Evol. 20, 367373

Ghini, S., Fernandez, M., Pico, Y., Marin, R., Fini, F., Manes, J., Girotti, S. (2004) Occurrence and distribution of pesticides in the province of Bologna, Italy, Using honey bees as bioindicators. Arch. Environ. Contam. Toxicol. 47, 479-488

Hall, P. (2010) GC/MS and GC/MS/MS Analysis and Atmospheric Concentrations Organochlorine and Organophosphorus Pesticides and Selected Current Us Herbicides in Saskatchewan. Ph D Thesis, University of Regina

Health Canada, Consumer Product Safety, Pest Control Products Sales Report for 2007 and 2008, available at http://www.hc-sc.gc.ca/cps-spc/pubs/pest/_corp-plan/ sales-2007-2008-ventes/index-eng.php Āgriculture. Accessed 6 Jan 2015

Johnson, R.M., Ellis, M.D., Mullin, C.A., Frazier, M. (2010) Pesticides and honey bee toxicity-U.S.A. Apidologie 41, 312-331

Lehotay, S.J., Mastovska, K., Lightfield, A.R. (2005) Use of buffering and other means to improve results of problematic pesticides in a fast and easy method for residue analysis of fruits and vegetables. J. A.O.A.C. Int. 88, 615-629

Mullin, C.A., Frazier, M., Frazier, J.L., Ashcraft, S., Simonds, R., VanEngelsdorp, D., Pettis, J.S. (2010) High Levels of Miticides and Agrochemicals in North American Apiaries: Implications for Honey Bee Health. PLoS One 5(3), e9754. doi:10.1371/ journal.pone.0009754

Pico, Y., Font, G., Molto, J.C., Manes, J. (1996) In: Nollet, L.M.L. (ed.) Food Analysis, p. 717. HPLC. Dekker, New York. Chapter 17

Raina, R., Hall, P., Sun, L. (2010) Occurrence and relationship of organophosphorus insecticides and their degradation products in the atmosphere in western Canada agricultural regions. Environ. Sci. Technol. 44 (22), 8541-8546

Rissato, S.R., Galhiane, M.S., De Almeida, M.V., Gerenutti, M., Apon, B.M. (2007) Multiresidue determination of pesticides in honey samples by gas chromatographymass spectrometry and application in environmental contamination. Food Chem. 101, 1719-1726

Saskatchewan Usage Inventory (2003) Personnel Communication, Saskatchewan. http://ourspace.uregina.ca/ b i t s tre a m/h a nd le/10294/5299/ Alzahrani_Noof_Edan_200273512_MSC_CHEM_F-

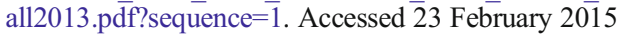

Seeley, T.D. (1985) Honeybee ecology: a study of adaptation in social life. Princeton University Press, Princeton, NJ

Snodgrass, R.E. (1975) The Anatomy of the Honey Bee. In: Veatch, E. (ed.) The Hive and the Honey Bee, pp. 75124. Dadant \& Sons, Hamilton, IL

Solomon, K.R., Williams, M., Mackay, D., Purdy, J., Giddings, J.M., Giesy, J.P. (2014) Properties and uses of chlorpyrifos in the United States. In: Giesy, J.P., 
Solomon, K.R. (eds.) In: Ecological risk assessment for Chlorpyrifos in Terrestrial and Aquatic systems in United states. Rev. Environ. Contam. Toxicol, vol. 231, pp. 13-34

USDA, (2007) Agriculture Secretary Mike Johanns addressed the problem of honeybee colony collapse disorder. USDA Satellite News Feed July 5, 2007. http:// w3.usda.gov/agency/oc/bmtc/scripts.htm.

USEPA, (2012) White Paper in Support of the Proposed Risk Assessment Process for Bees. Office of Chemical Safety and Pollution Prevention, Office of Pesticide Programs, Environmental Fate and Effects Division, United States Environmental Protection Agency, Washington, DC. http://www.cdpr.ca.gov/docs/emon/surfwtr/presentations/epa_whitepaper.pdf
VanEngelsdorp, D., Meixner, M.D. (2010) A historical review of managed honey bee populations in Europe and the United States and the factors that may affect them. J. Invertebr. Pathol. 103, S80-S95

Wiest, L., Bulete, A., Giroud, B., Fratta, C., Amic, S., Lambert, O., Pouliquen, H., Arnaudguilhem, C. (2011) Multi-residue analysis of 80 environmental contaminants in honeys, honeybees and pollens by one extraction procedure followed by liquid and gas chromatography coupled with mass spectrometric detection. J. Chromatogr. A 1218, 57435756

Willmer, P. (2011) Pollination and Floral Ecology. Princeton University Press, Princeton, NJ. 828 